\title{
Urinary excretion of non-dialysable conjugates of glucose and galactose in normal people and diabetic patients
}

\author{
P. Lloyd ${ }^{1}$, T. D. R. Hockaday ${ }^{2}$ and P.J. Randle ${ }^{1}$ \\ ${ }^{1}$ Nuffield Department of Clinical Biochemistry, John Radcliffe Hospital and ${ }^{2}$ Radcliffe Infirmary, Oxford, UK
}

\begin{abstract}
Summary. Urine contains non-dialysable conjugates of glucose and galactose from which the free sugars are released by acid hydrolysis. In 14 non-diabetic subjects the 24 -h outputs (mean \pm SEM) were $25 \pm 3 \mu \mathrm{mol} / 24 \mathrm{~h}$ (glucose) and $109 \pm$ $15 \mu \mathrm{mol} / 1$ (galactose). In collections from 23 diabetic patients output of conjugated glucose was increased to $177 \pm$ $96 \mu \mathrm{mol} / 24 \mathrm{~h}$ but conjugated galactose was unchanged $(119 \pm 10 \mu \mathrm{mol} / 24 \mathrm{~h})$. The concentration ratio of glucosyl/galactosyl allows relative $24-\mathrm{h}$ outputs of conjugated glucose to be estimated on random samples. The ratio (mean \pm SEM) was $0.24 \pm 0.01$ in 27 normal men and $0.37 \pm 0.04$ in 30 normal women. The mean ratio was increased to $0.72 \pm 0.20$ in 56 male and to $0.51 \pm 0.07$ in 17 female diabetic patients. In individual diabetic patients, the ratio was increased significantly in 28 out of 56 men and in 5 out of 30 women. In male diabetic
\end{abstract}

patients the ratio was increased in 17 out of 23 Type 1 (insulindependent) but in only 3 out of 15 Type 2 (non-insulin-dependent) diabetic patients. There was no correlation between the glucosyl/galactosyl ratio and patient age, known duration of diabetes, or urinary excretion of free glucose or protein. Urine samples showing increased glucosyl/galactosyl ratios did not yield bacteria on culture and were negative for Candida albicans cell-wall mannan antigen. It is concluded that $80 \%$ of male Type 1 diabetic patients show increased urinary excretion of non-dialysable conjugated glucose. In women, there is much greater variation in non-diabetic subjects which may obscure an increased excretion in diabetic patients.

Key words: Urinary conjugated glucose, urinary glucosyl/galactosyl ratio, Type 1 diabetes, Type 2 diabetes.
During investigation whether analysis of urinary glycopeptides might yield information about renal pathology in diabetic patients, analyses of glucose and galactose were performed on acid hydrolysates of non-dialysable material in urine. These analyses showed that substantial quantities of non-dialysable conjugated glucose and galactose are present in urine, and that the urinary output of conjugated glucose and the concentration ratio of conjugated glucose/conjugated galactose are increased in some diabetic patients. We describe here the result of an investigation of this phenomenon and its relation to diabetes. A preliminary report on these findings has been published [1].

\section{Subjects and methods}

\section{Subjects}

Control subjects (except for six elderly people) were healthy laboratory workers comprising 30 females (mean \pm SEM age: $36 \pm 3$ years, range $21-72$ years) and 27 males (mean age: $45 \pm 3.5$ years, range 24-90 years). Their 24-h urine collections were obtained in the course of normal daily life; random urine samples were mid-stream specimens voided during the day. Diabetic patients were either outpatients attending for control of diabetes (random urine samples; mid-stream specimens) or hospital in-patients (24-h collections). They comprised 17 females (mean age: $42 \pm 4.6$ years, range $21-70$ years) and 56 males (mean age: $52 \pm 2.3$ years, range $22-77$ years). There were no significant differences in mean or variance of age between the groups of diabetic and non-diabetic subjects. The criteria for Type 1 (insulin-dependent) diabetes were age of onset $<30$ years, and a well-established requirement for insulin (except in two patients requiring insulin to prevent ketonuria where the age of onset was $>60$ years). The criteria for Type 2 (non-insulin-dependent) diabetes were age of onset $>$
40 years and diabetes controlled without insulin (except for one patient receiving 16 units of monotard insulin per day and with no known episode of ketonuria).

\section{Methods}

Urine was kept at $4^{\circ} \mathrm{C}$ during collection in containers with merthiolate (final concentration $>100 \mathrm{mg} / \mathrm{l}$ ), which sufficed to prevent growth of micro-organisms. Urine samples were dialysed immediately on completion of collection in Visking seamless tubing (Scientific Instrument Centre, London, UK), sterilised, and freed of plasticisers by boiling [2], and stored at $4{ }^{\circ} \mathrm{C}$ in sodium azide $(0.01 \% \mathrm{wt} / \mathrm{vol})$. Dialysis was for $48 \mathrm{~h}$ at $4^{\circ} \mathrm{C}$ against running tap-water, followed by dialysis against more than three changes of distilled water over $18 \mathrm{~h}$ at $4^{\circ} \mathrm{C}$. After dialysis, free glucose concentration was $<20 \mu \mathrm{mol} / 1$. Urine samples containing blood (test strip, Boehringer, Mannheim, FRG, BM-test-7) were discarded. Sterility of samples after dialysis was ascertained by culture on blood agar plates; samples which yielded growth of micro-organisms were discarded. Some random urine samples were cultured before addition of merthiolate. Urine powders (see below) were tested at 1 and $10 \mathrm{~g} / 1$ by agar-gel double-diffusion against two sera containing antibodies to Candida albicans cell-wall mannan antigen. No precipitin reactions were seen.

Dialysed urine was freeze-dried and stored at $-18^{\circ} \mathrm{C}$ in air-tight containers. Free glucose and galactose were released from conjugates by hydrolysis in $\mathrm{H}_{2} \mathrm{SO}_{4}(1 \mathrm{~mol} / \mathrm{l})$ at $110^{\circ} \mathrm{C}$ for $6 \mathrm{~h}$ in sealed tubes (4-10 g powder $/ 1$ ). Maximum release was achieved in $4 \mathrm{~h}$, and in control experiments with glucose and galactose recoveries were $78 \%$ and $77 \%$, respectively. The hydrolysate was brought to $\mathrm{pH} 7.5$ by addition of an equal volume of [triethanolamine- $\mathrm{HCl} \quad(0.5 \mathrm{~mol} / 1$; $\mathrm{pH} 7.5)+\mathrm{KOH}(2 \mathrm{~mol} / \mathrm{l})]$. Glucose and galactose $(10-100 \mathrm{nmol})$ were assayed spectrophotometrically $(\times 3)$ employing hexokinase/glucose 6-phosphate dehydrogenase [3] or galactose dehydrogenase [4].

The presence of protein, glucose and ketone bodies in urine samples was ascertained by test strip (Boehringer, BM-Test-7). Peptides were estimated in urine powder by the method of Lowry et al. [5]. For detection of glucosyl galactosyl hydroxylysine (GGH), $200 \mathrm{mg}$ of 
Table 1. Non-dialysable conjugates of glucose and galactose in random specimens and 24-h collections of urine from normal and diabetic subjects

\begin{tabular}{llcll}
\hline Subjects & Sample & $\begin{array}{l}\text { Glucosyl/ } \\
\text { galactosyl } \\
\text { ratio }\end{array}$ & $\begin{array}{l}\text { Glucose } \\
(\mu \mathrm{mol} / 24 \mathrm{~h})\end{array}$ & $\begin{array}{l}\text { Galactose } \\
(\mu \mathrm{mol} / 24 \mathrm{~h})\end{array}$ \\
\hline Normal & $\begin{array}{l}24 \mathrm{~h} \\
(n=14)\end{array}$ & $\begin{array}{c}0.23 \pm 0.01 \\
(0.16-0.33)\end{array}$ & $\begin{array}{c}25 \pm 3 \\
(6-40)\end{array}$ & $\begin{array}{l}109 \pm 15 \\
(33-244)\end{array}$ \\
Diabetic & $24 \mathrm{~h}$ & $1.27 \pm 0.46^{\mathrm{a}}$ & $177 \pm 96^{\mathrm{a}}$ & $119 \pm 10$ \\
& $(n=23)$ & $(0.16-10)$ & $(27-2251)$ & $(53-222)$ \\
Male normal & $\begin{array}{l}\text { Random } \\
(n=27)\end{array}$ & $\begin{array}{c}0.24 \pm 0.01 \\
(0.15-0.33)\end{array}$ & - & - \\
Male diabetic & $\begin{array}{l}\text { Random } \\
(n=56)\end{array}$ & $0.72 \pm 0.20^{\mathrm{a}}$ & - & - \\
Female normal & $\begin{array}{l}\text { Random } \\
(n=30)\end{array}$ & $0.37 \pm 0.04$ & - & - \\
& $(0.14-1)$ & & - \\
Female & $\begin{array}{l}\text { Random } \\
\text { diabetic }\end{array}$ & $0.51 \pm 0.07^{\mathrm{b}}$ & - & - \\
\hline
\end{tabular}

Results are mean $\pm S E M$ with ranges in parentheses

a $p<0.001$ for difference (diabetic - normal) based on means of $\log _{10}$ (glucosyl/galactosyl ratio) or $\log _{10}$ (24-h output of glucose). The variances did not differ significantly $(p>0.05)$ when logarithmic values were used but did differ significantly when natural values were used. ${ }^{b} 0.02<p<0.05$ employing natural values (variances did not differ significantly). The 24-h collections were from normal male subjects and from 19 male and 4 female diabetic patients

urine powder were heated at $100^{\circ} \mathrm{C}$ for $24 \mathrm{~h}$ in $10 \mathrm{ml}$ of aqueous $\mathrm{KOH}$ $(2 \mathrm{~mol} / \mathrm{l})$ in sealed tubes. The hydrolysate was cooled and neutralised with $\mathrm{HClO}_{4}$ and the supernatant loaded onto a $10-\mathrm{ml}$ column of Dowex $50 \mathrm{H}^{+}(\mathrm{Bio}-\mathrm{Rad}$ Laboratories, Watford, UK) and washed with water $(50 \mathrm{ml})$. GGH was eluted with $50 \mathrm{ml} \mathrm{NH} \mathrm{NH}_{4} \mathrm{OH}(2 \mathrm{~mol} / \mathrm{l})$ and freeze dried. The residue was taken up in water $(1 \mathrm{ml})$ and $20 \mu \mathrm{l}$ subjected to high-voltage paper electrophoresis at $3 \mathrm{kV}$ for $30 \mathrm{~min}$ on Whatman 3MM paper at pH3.5 (aqueous acetic acid $5 \%$ by volume + pyridine $0.5 \%$ by volume). An authentic sample of GGH ( $10 \mathrm{nmol}$; kindly provided by Dr. R.G.Spiro of Harvard University Medical School, Boston, USA) was run at the same time. The paper was dried and stained with ninhydrin in acetone $(1 \mathrm{mg} / \mathrm{ml}) ; R_{\mathrm{f}}$ values relative to hydroxylysine were $0.60(\mathrm{GGH})$ and 0.73 (galactosylhydroxylysine).

\section{Statistical analyses}

The significance of differences between means was determined by Student's t-test, using log-transformed data where appropriate. The significance of differences between variances of means was determined by the variance ratio $(\mathrm{F})$. The significance of correlation between variables was determined by calculation of the correlation coefficient (r) and by least-squares linear regression analysis.

\section{Results}

Urinary outputs of conjugated glucose and galactose in diabetic and control subjects

Initial studies showed that the mean 24-h urinary output of non-dialysable conjugated glucose was increased approximately sevenfold (range 1.1 to 81 -fold) in 23 collections from diabetic patients (19 male, 4 female) as compared with 14 collections from control subjects (all male; Table 1). In the same collections the mean outputs of conjugated galactose did not differ significantly. This suggested that the concentration ratio of conjugat- ed glucose/conjugated galactose (glucosyl/galactosyl ratio) in random samples could provide a valid basis for comparing urinary excretion of conjugated glucose. This conclusion is supported by the correlation between the 24-h output of conjugated glucose and the glucosyl/ galactosyl ratio (Fig. $1 ; r=0.88 ; p<0.001$ ). The slope $(117 \pm 7.9$ mean $\pm \mathrm{SEM})$, which is the 24 -h output of conjugated galactose, is in excellent agreement with the values shown in Table 1 . For reasons of clarity in presentation, four diabetic patients with very high outputs of conjugated glucose $(115,155,489$ and $2251 \mu \mathrm{mol} /$ $24 \mathrm{~h})$ and very high glucosyl/galactosyl ratios $(2.2,2.6$, 5.3 and 10 respectively) are excluded from Figure 1 . The average 24-h output of conjugated galactose in these four patients $(107 \mu \mathrm{mol})$ was comparable to the values for control subjects and for the whole group of diabetic patients.

\section{Urinary glucosyl/galactosyl concentration ratio in diabetic and control subjects}

Urinary glucosyl/galactosyl ratios for 57 control subjects ( 27 male, 30 female) and 73 diabetic patients (56 male and 17 female) are shown in Table 1 (mean values) and Figure 2 (individual values). In male control subjects the individual values showed an approximately twofold range about a mean of 0.23 . Repeat analysis on random samples collected over periods of up to 2 years showed only small variation within the normal range (results not shown). In male diabetic patients the mean ratio was increased approximately fivefold over control subjects (range 1.1 to 43 -fold) and in 28 out of 56 patients investigated, the ratio exceeded significantly the mean value for controls (greater than mean $+2 \mathrm{SD}$ ). Repeat analyses on samples from male diabetic patients with increased ratios over the course of 1 month showed that the ratio remained elevated (results not shown).

The urinary glucosyl/galactosyl ratio in female control subjects showed considerable variation (approximately tenfold) about a mean of 0.23 (Table 1, Fig. 2). Repeat analyses on three samples collected over a 33-day period showed considerable variation between samples (up to tenfold) in 8 of the 11 women studied (age range 21-48 years). The variation showed no obvious dependence on the day of the menstrual cycle (results not shown). The mean glucosyl/galactosyl ratio was elevated in female diabetic patients (approximately 1.5 -fold) but in only 5 out of 30 patients was the individual ratio significantly greater than the mean for control subjects (Table 1, Fig. 2).

There was no correlation between the glucosyl/galactosyl ratio and the concentration of peptides in dialysed urine of control and diabetic subjects $(r=0.24$, $p>0.1$; Fig.3). For reasons of clarity in presentation, samples from two diabetic patients with ratios of 0.24 and 0.74 and peptide concentrations of 4.8 and $2.1 \mathrm{~g} / \mathrm{l}$, respectively, were excluded from Figure 3 . In all but two of the diabetic patients studied the urinary excretion of non-dialysable peptides exceeded that in control sub- 


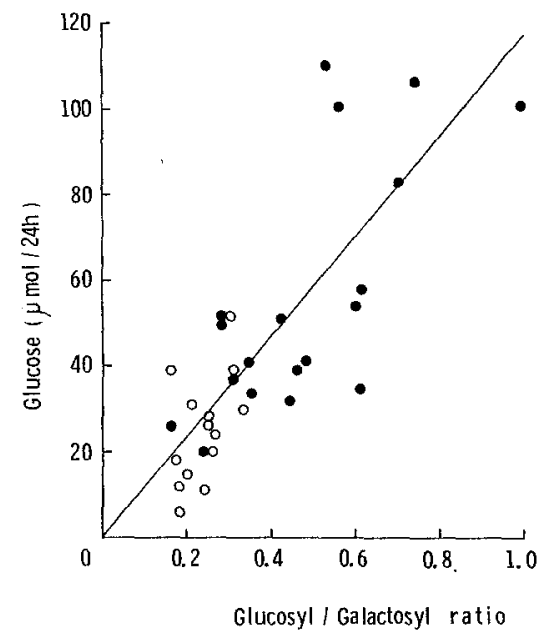

Fig. 1. Correlation between 24-h urinary excretion of non-dialysable glucose conjugates and the concentration ratio of conjugated glucose/conjugated galactose. Normal subjects $(O)$, diabetic subjects (O). Data from four diabetic subjects omitted (see text). Slope (mean $\pm \mathrm{SEM}$ ) $117 \pm 7.9 \mu \mathrm{mol}$ galactose $/ 24 \mathrm{~h} ; r=0.88, p<0.001$. The intercept is, by definition, zero and this restriction was imposed on the regression analysis

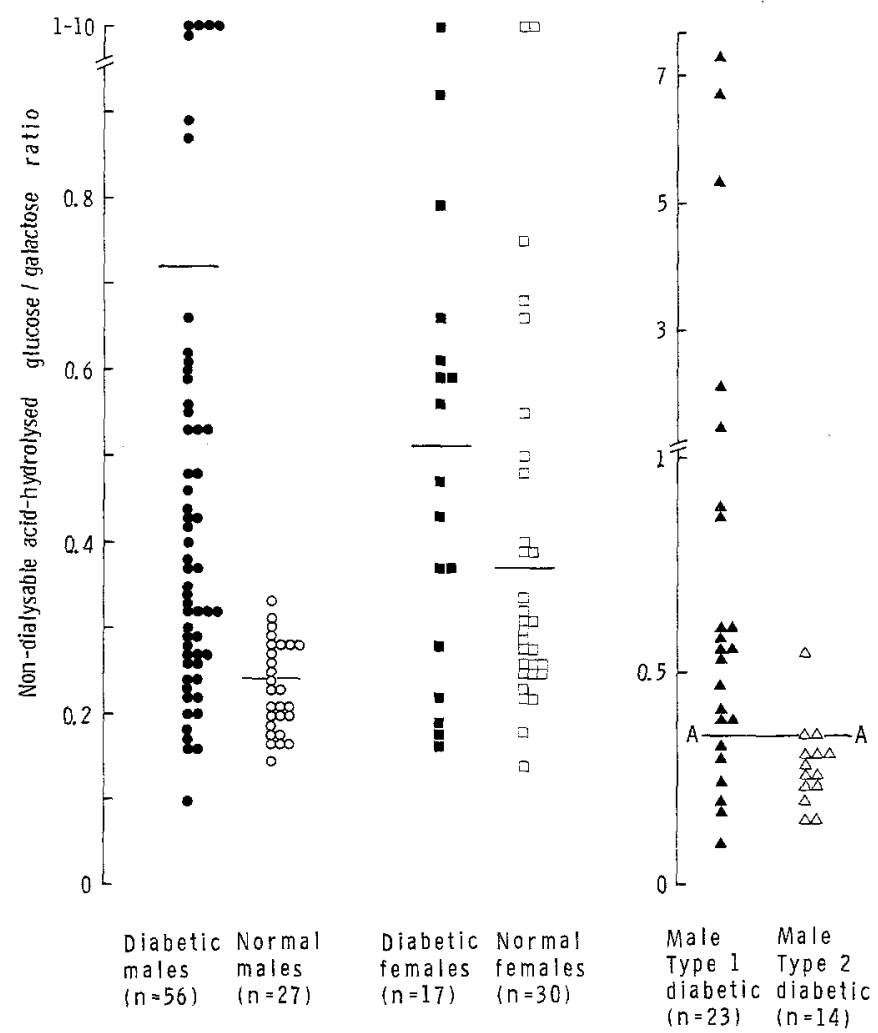

Fig. 2. Individual values of the concentration ratio of (non-dialysable) conjugated glucose/conjugated galactose in random samples of urine. In columns 1-4 the horizontal line represents the mean of each group. In columns 5 and 6 the horizontal line $\mathrm{A}-\mathrm{A}$ is the upper limit of the normal range in men (mean $+2 \mathrm{SD})$

jects (greater than mean $+2 \mathrm{SD}$ ). However proteinuria as detected by stick test on the 24-h collections (Table 1 and Fig. 1) was absent in 22 of the 23 diabetic patients studied. The one diabetic sample which gave a positive test for protein had a glucosyl/galactosyl ratio of 0.74 which was not significantly different from the mean ra-

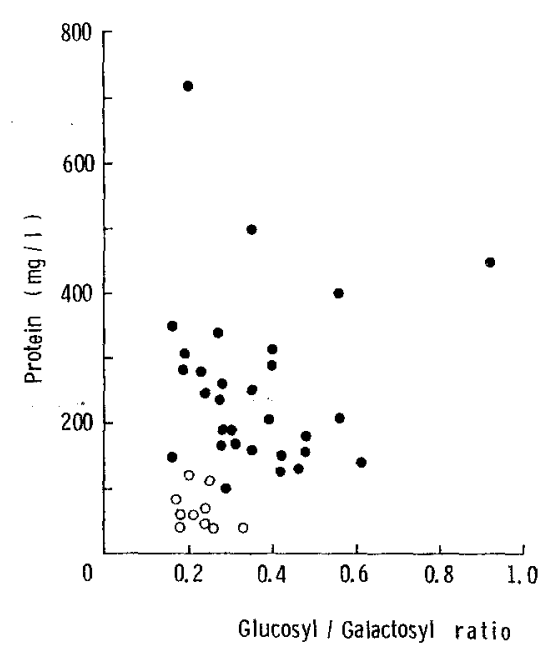

Fig.3. Correlation between non-dialysable peptides and the (nondialysable) concentration ratio of glucosyl/galactosyl in random samples of urine. Normal subjects $(O)$, diabetic subjects $(\mathbf{O}) ; r=0.24$; $p>0.1$. Data from two diabetic subjects omitted (see text)

tio (0.66) for the whole group (Table 1). We conclude that increased glucosyl/galactosyl ratio and increased urinary excretion of conjugated glucose are neither correlated with the urinary excretion of peptides nor dependent upon proteinuria as detected by stick test.

Glucose is not a common constituent of glycoproteins [6] but it is found in some glycoproteins as glucosyl-galactosyl-hydroxylysine $(\mathrm{GGH})$. The urinary output of GGH in peptides is low $(<0.5 \mu \mathrm{mol} / 24 \mathrm{~h}$ in control and diabetic subjects in the present study, $1.1-1.7 \mu \mathrm{mol} / 24 \mathrm{~h}$ in [7]) in relation to the overall excretion of conjugated glucose (Table 1).

Addition of glucose (final concentration $20 \mathrm{mmol} / 1$ ) to urine samples from normal subjects before dialysis had no effect on the concentration of conjugated glucose or the glucosyl/galactosyl ratio (results not shown). High glucosyl/galactosyl ratios $(0.91,1.10)$ were observed in mid-stream urine samples, sterile on culture and devoid of cells or casts by light microscopy, which were collected from male diabetic subjects in the absence of merthiolate. Urine samples exhibiting high glucosyl/galactosyl ratios may yield insoluble material containing conjugated glucose and galactose which is stained red by basic fuchsin. However this material was present in urines from both control and diabetic subjects; its contribution to the urinary excretion of conjugated glucose was $<2 \%$ and its removal had no effect on the glucosyl/galactosyl ratio. We conclude that the increased glucosyl/galactosyl ratio and increased urinary excretion of conjugated glucose in diabetic patients are not due to cells or bacteria, or to insoluble material derived from cells or bacteria.

In diabetic patients (male + female) there was no correlation between glucosyl/galactosyl ratio and either patient age ( $r=-0.09, p>0.1$ for 56 patients) or known duration of diabetes $(r=0.24, p>0.1$ for 49 patients). High ratios have been seen with diabetes ranging in known duration from 1 year (ratio 1.46) to 44 years (ratio 0.61 ). There was no correlation between glucosyl/ 
galactosyl ratio and urinary glucose concentration. Raised glucosyl/galactosyl ratios (0.56-0.92) were seen in five diabetic patients with urinary glucose concentrations ranging from $0.21-15 \mathrm{mmol} / 1$ and normal ratios (0.16-0.29) accompanied urinary glucose concentrations ranging from $0-12.6 \mathrm{mmol} / 1$ ( 10 patients). There was no correlation in 17 patients between urinary glucose concentration and glucosyl/galactosyl ratio $(r=-0.07, p>0.1)$ (results not shown).

Glucosyl/galactosyl ratios in relation to type of diabetes are shown in Figure 2. Criteria of typing (which was carried out without knowledge of the glucosyl/galactosyl ratio) are given in the Subjects and Methods Section. In male Type 1 diabetic patients glucosyl/galactosyl ratio was elevated significantly in 17 out of 23 (mean ratio $1.35 \pm 0.45$, range $0.10-8.3$; mean duration of diabetes 15 years, range 3-30 years). In male Type 2 diabetic patients the ratio was elevated significantly in only 3 out of 14 (mean ratio $0.25 \pm 0.025$, range $0.16-0.55$; mean duration of diabetes 8 years, range 1-16 years). We have excluded from this analysis any male diabetic patients where type of diabetes was in doubt. Females were excluded from the analysis because of substantial variation of the ratio in control subjects. We conclude that increased glucosyl/galactosyl ratio and increased urinary excretion of conjugated glucose in men are associated predominantly with Type 1 diabetes.

\section{Discussion}

The present study has shown that urine contains substantial amounts of non-dialysable conjugates of glucose and galactose, that the urinary excretion of conjugated glucose may be deduced from the concentration ratio of glucosyl/galactosyl, and that excretion of conjugated glucose (but not conjugated galactose) is increased in approximately $80 \%$ of Type 1 male diabetic patients. In female control subjects the ratio was more variable, the mean ratio was higher than in men, and the effect of diabetes in women was as a consequence less certain. The glucosyl/galactosyl ratios in some urine samples from some non-diabetic women were comparable to ratios seen in urine samples from diabetic patients of either sex. It follows that, in women, high gluco$\mathrm{syl} /$ galactosyl ratios are not peculiar to diabetes.

These findings were initially fortuitous and empirical and to the best of our knowledge they are new observations. Since this work was begun (in 1979) Honda et al. [8] have described non-dialysable glycoconjugates in urine analysed by gas chromatography after acid hydrolysis and derivatisation. The mean glucosyl/galactosyl ratio in [8] was 0.22 ; the ratio in our own study $(0.23)$ is in close agreement. Honda et al. performed no studies in diabetic patients but they observed an increased ratio in cancer patients $(0.56 \pm 14$, mean $\pm S E M)$. The number of observations was small (10 controls, 15 cancer patients) and results for men and women were not re- corded or segregated. It is not possible therefore to ascertain whether the apparent effect of cancer may have been due to a greater preponderance of women in the group of cancer patients than in the control subjects.

We have shown in the present study that an increased glucosyl/galactosyl ratio and hence increased urinary excretion of conjugated glucose in diabetic patients was associated predominantly with Type 1 diabetes. The ratio and hence urinary excretion of conjugated glucose was not correlated with age, known duration of diabetes or urinary excretion of glucose or protein. We have not attempted in this study to ascertain whether the ratio or excretion of conjugated glucose is related to the degree of control of glycaemia, or to any criteria of renal dysfunction other than proteinuria (stick test) or excretion of non-dialysable peptides. It seems to us important to attempt to characterise the molecular species which may be responsible for the increased excretion of conjugated glucose in diabetic patients before embarking on further studies of the clinical usefulness and significance of the observation.

Acknowledgements. This work was supported by grants from the Medical Research Council (UK), The British Diabetic Association, the Medical Research Fund (University of Oxford) and the Wellcome Trust. We thank Dr. M. S. Dunnill for microscopy of insoluble material in urine and Dr. J. Faux for Candida albicans mannan antigen assays.

\section{References}

1. Lloyd P, Randle PJ (1982) Diabetes and the excretion of urinary glycoconjugates. Diabetologia 23: 470 (Abstract)

2. Garland PB, Newsholme EA, Randle PJ (1964) Regulation of glucose uptake by muscle. Biochem J 93: 665-678

3. Bergmeyer HU, Bernt E, Schmidt F, Stork H (1974) D-glucose: Determination with hexokinase and glucose 6-phosphate dehydrogenase. In: Bergmeyer HU (ed) Methods of enzymatic analysis, Vol 3. Verlag Chemie, New York, London, pp 1196-1201

4. Kurz G, Wallenfels K (1974) D-galactose: UV-assay with galactose dehydrogenase. In: Bergmeyer HU (ed) Methods of enzymatic analysis, Vol 3. Verlag Chemie, New York, London, pp 1279-1282

5. Lowry OH, Rosebrough NJ, Farr AL, Randall RJ (1951) Protein measurement with the Folin phenol reagent. J Biol Chem 193: 265-275

6. Lundblad A (1978) Urinary glycoproteins, glycopeptides and oligosaccharides. In: Horowitz MI, Pigman W (eds) The glycoconjugates, Vol 1. Academic Press, New York, London, pp 441-458

7. Askenasi R (1978) The origin of the urinary glucosyl-galactosyl-hydroxylysine: interstitial collagen, GBM, or Clq? In: Kefalides NA (ed) Biology and chemistry of basement membranes. Academic Press, New York, London, pp 443-451

8. Honda A, Suzuki S, Kakehi K, Honda A, Takai T (1981) Analysis of the monosaccharide compositions of total non-dialysable urinary glycoconjugates by the dithioacetal method. J Chromatogr 226: 341-350

Received: 30 January 1984

and in revised form: 14 June 1984

Professor P.J. Randle

Nuffield Department of Clinical Biochemistry

John Radcliffe Hospital

Oxford OX3 9DU, UK 